\title{
MicroRNA-215 suppresses the proliferation, migration and invasion of non-small cell lung carcinoma cells through the downregulation of matrix metalloproteinase-16 expression
}

\author{
YUANSHAN YAO, HAIBO SHEN, YINJIE ZHOU, ZHENHUA YANG and TIANJUN HU \\ Department of Chest Surgery, Ningbo No. 2 Hospital, Ningbo, Zhejiang 315000, P.R. China
}

Received April 29, 2017; Accepted December 15, 2017

DOI: $10.3892 /$ etm.2018.5869

\begin{abstract}
The present study investigated the expression of microRNA (miR)-215 in non-small cell lung carcinoma (NSCLC) at tissue and cellular levels, as well as its biological functions and mechanism of action. A total of 56 patients with NSCLC were included in the present study. NSCLC tissues and tumor-adjacent normal tissues were resected and collected. Reverse transcription-quantitative polymerase chain reaction was used to measure the expression of miR-215. Following transfection with miR-215 mimics, A549 cell proliferation, migration and invasion were determined using a Cell Counting Kit-8 and Transwell assay. Western blotting was employed to measure the expression of matrix metalloproteinase (MMP)-16 protein. A dual-luciferase reporter assay was conducted to determine the existence of a direct interaction between miR-215 and the MMP-16 gene. Reduced expression of miR-215 in NSCLC was closely associated with lymphatic metastasis and TNM staging. Overexpression of miR-215 inhibited the proliferation of A549 cells in vitro. Upregulated expression of miR-215 inhibited the migration and invasion of A549 cells in vitro. miR-215 exerted its biological functions possibly by regulating the expression of MMP-16. Elevated expression of MMP-16 promoted the proliferation, migration and invasion of A549 cells. miR-215 regulated the proliferation, migration and invasion of A549 cells by binding with the seed 3'-untranslated region of MMP-16 mRNA. The present study demonstrates that reduced expression of miR-215 in NSCLC is negatively associated with lymphatic metastasis and TNM staging. In addition, miR-215 acts as a tumor suppressor gene by inhibiting the proliferation, migration and invasion of NSCLC cells via the downregulation of MMP-16 expression.
\end{abstract}

Correspondence to: Dr Haibo Shen, Department of Chest Surgery, Ningbo No. 2 Hospital, 41 Xibei Street, Ningbo, Zhejiang 315000, P.R. China

E-mail: yys12yys@126.com

Key words: microRNA-215, non-small cell lung carcinoma, matrix metalloproteinase-16

\section{Introduction}

Lung cancer has the highest incidence and mortality of all malignant tumors worldwide, and it severely threatens people's health (1-3). China's cancer registration report in 2013 demonstrated that the incidence and mortality of lung cancer ranked the first in cities and rural areas (4). Therefore, the prevention and treatment of lung cancer has become a focus in medicine. Primary lung cancer includes small cell lung carcinoma (SCLC) and non-SCLC (NSCLC), and NSCLC cases account for $~ 85 \%$ of all lung cancer cases (2). Surgical treatment is the most effective method for the treatment of NSCLC. Although surgical treatment has been greatly developed in recent years, the prognosis for patients with NSCLC remains poor, with a 5-year survival rate of only $\sim 16 \%$ (5). Tumor recurrence and metastasis are the predominant causes of treatment failure in patients with NSCLC (6); however, the molecular mechanisms of NSCLC are not yet clear. It has been reported that various genes are involved in the regulation of proliferation, drug resistance, apoptosis, invasion and metastasis of NSCLC (7); therefore, molecular targeted therapy for NSCLC has demonstrated great clinical significance (8). However, the therapeutic targets for NSCLC remain to be further studied due to the complex molecular mechanisms of the disease.

MicroRNA (miR), with a length of 18-25 nt, are important regulatory factors in the occurrence and development of tumors, and are also targets for tumor diagnosis and treatment (9). miR bind with the 3'-untranslated region (UTR) of mRNA and regulate gene expression by inhibiting mRNA translation (10). $\mathrm{miR}$ molecules may serve the roles of oncogenes or tumor suppressor genes, and expression imbalance is a crucial factor in the development of cancer (11). Studies have revealed that miR molecules are involved in the proliferation, invasion and metastasis of NSCLC. Pei et al (12) demonstrated that miR-185-5p regulates the chemotherapy resistance of NSCLC by targeting the ABCC1 gene (multidrug resistance-associated protein 1). Sun et al (13) reported that miR-9600 inhibits the proliferation and metastasis of NSCLC by targeting signal transducer and activator of transcription 3 gene expression. Wang et al (14) indicated that miR-509-5p inhibits the proliferation and invasion of NSCLC by targeting YWHAG gene (14). These studies indicate that miR molecules are involved in the occurrence and development of NSCLC.

miR-215 is a newly discovered tumor-associated miR molecule that has varied functions in multiple tumor types. For 
example, miR-215 promotes the proliferation and metastasis of glioma cells by targeting retinoblastoma tumor suppressor gene 1 (15). Additionally, miR-215, as an oncogene, promotes the development of gastric cancer cells by downregulating the expression of the Runt-related transcription factor 1 gene (16). $\mathrm{Li}$ et al (17) discovered that miR-215 directly regulates the zinc finger E-box-binding homeobox 2 (ZEB2) gene and inhibits the epithelial-mesenchymal transition of pancreatic cancer cells, acting as a tumor suppressor gene (17). In addition, miR-215 has the function of a tumor suppressor gene in NSCLC and is regulated by its upstream transcription factor, p53. It inhibits the proliferation and invasion and promotes the apoptosis of NSCLC cells (18). However, the downstream regulatory mechanism of miR-215 remains to be further studied. In the present study, the expression of miR-215 and its mechanism of action in NSCLC was investigated.

\section{Materials and methods}

Patients. A total of 56 patients with NSCLC (27 males and 29 females) who were subjected to resection of tumor tissues (NSCLC group) and tumor-adjacent tissues (normal group) at Ningbo No. 2 Hospital (Ningbo, China) between January 2014 and November 2015 were included in the present study. The resected tissues were stored at $-80^{\circ} \mathrm{C}$ prior to use. The age range of the patients was 29-73 years, and the mean age was $46.7 \pm 1.8$ years. None of the patients received adjuvant therapy prior to surgery. Among these patients, 32 had lymphatic metastasis (N1 group) and 24 had no lymphatic metastasis (N0 group). According to the TNM staging standards of the American Joint Committee on Cancer published in 2003 (19), 17 patients were at stage I, 22 patients were at stage II, 8 patients were at stage III and 9 patients were at stage IV. All procedures were approved by the Ethics Committee of Ningbo No. 2 Hospital. Written informed consent was obtained from all patients or their families.

Cells. Lung cancer A549 cell line was purchased from Shanghai Institute of Cell Biology, Chinese Academy of Sciences (Shanghai, China). A549 cells were defrosted at $37^{\circ} \mathrm{C}$ and cultured in $10 \mathrm{ml}$ fresh Dulbecco's modified Eagle's medium (DMEM; Thermo Fisher Scientific, Inc., Waltham, MA, USA) at $37^{\circ} \mathrm{C}$ and $5 \% \mathrm{CO}_{2}$ for $24 \mathrm{~h}$. After $24 \mathrm{~h}$ of incubation, the old medium was discarded, and $5 \mathrm{ml}$ fresh high-glucose DMEM supplemented with $10 \%$ fetal bovine serum (FBS; Thermo Fisher Scientific, Inc.) was added for subsequent culture. The medium was replaced every 2 days, and the cells were passaged when a confluency of $90 \%$ was reached.

A549 cells ( $1 \times 10^{5} /$ well) were seeded into 24 -well plates and divided into an miR-negative control (NC) group and an miR-215 mimics group. When $70-90 \%$ confluency was reached, $1.25 \mu 1 \mathrm{miR}-215 \mathrm{mimic}$ (5'-ATGACCTATGAA TTGACAGAC-3') or miR-NC (5'-TGACATAGACTAGCT CATACGA-3') (20 pmol/ $/ \mathrm{l}$; Guangzhou RiboBio Co., Ltd., Guangzhou, China) and $1 \mu$ Lipofectamine $2000^{\circledR}$ (Thermo Fisher Scientific, Inc.) were added into two individual vials containing $50 \mu \mathrm{l}$ Opti-Mem medium (Thermo Fisher Scientific, Inc.), respectively. After $5 \mathrm{~min}$, the liquids in the two vials were mixed together before being left to stand for an additional $15 \mathrm{~min}$. Subsequently, the mixture was added onto the cells for an incubation of $6 \mathrm{~h}$ before changing to DMEM supplemented with 10\% FBS. The cells were cultured for $48 \mathrm{~h}$ under normal conditions prior to use.

For the rescue assay, the aforementioned transfection procedure was performed with $0.5 \mu \mathrm{g}$ NC or pcDNA-3.1-MMP-16 plasmid DNA (Hanbio Biotechnology Co., Ltd., Shanghai, China).

Reverse transcription-quantitative polymerase chain reaction (RT-qPCR). Lung tissues (100 mg) were ground into powder using liquid nitrogen prior to the addition of $1 \mathrm{ml}$ TRIzol (Thermo Fisher Scientific, Inc.) for lysis. Following lysis, total RNA was extracted using the phenol chloroform method (20). The purity of RNA was determined by A260/A280 using ultraviolet spectrophotometry (Nanodrop ND2000; Thermo Fisher Scientific, Inc.). Subsequently, cDNA was obtained by RT using a TIANScript RT kit (Tiangen Biotech Co., Ltd., Beijing, China) from $1 \mu \mathrm{g}$ RNA and stored at $-20^{\circ} \mathrm{C}$. The RT reaction mixture was as follows: RNA template $(5 \mu \mathrm{l})$, Oligo dT $(2 \mu \mathrm{l})$, super pure dNTP $(2 \mu \mathrm{l})$ and $\mathrm{H}_{2} \mathrm{O}(5.5 \mu \mathrm{l})$. The reaction conditions involved heating to $70^{\circ} \mathrm{C}$ and sudden cooling on ice for 2 min before transient centrifugation at room temperature and $500 \mathrm{x}$ g for $30 \mathrm{sec}$. Subsequently, $4 \mu \mathrm{l} 5 \mathrm{X}$ first-strand buffer, $0.5 \mu \mathrm{l}$ RNasin and $1 \mu \mathrm{l}$ TIANScript M-MLV were added prior to gentle mixing with a pipette. After being kept at $25^{\circ} \mathrm{C}$ for $10 \mathrm{~min}$, the sample was incubated at $42^{\circ} \mathrm{C}$ for $50 \mathrm{~min}$, and then at $95^{\circ} \mathrm{C}$ for $5 \mathrm{~min}$ to terminate reactions.

For reverse transcription of miR-215, Universal cDNA Synthesis kit II (Takara, Dalian, China) was used. To determine the expression levels of miR-215 in tissues ExiLENT $\mathrm{SYBR}^{\circledR}$-Green master mix (Takara Biotechnology Co., Ltd.) was utilized, using GAPDH (forward, 5'-CTCGCTTCG GCAGCACA-3' and reverse, 5'-AACGCTTCACGAATTTG CGT-3') as an internal reference. The RT-qPCR reaction system (30 $\mu \mathrm{l}$ ) contained $5 \mu \mathrm{l} \mathrm{cDNA}, 10 \mu \mathrm{l}$ mix, $1 \mu \mathrm{l}$ upstream primer (miR-215, 5'-ATGACCTATGAATTGACAGAC-3'), $1 \mu \mathrm{l}$ downstream universal primer (provided by the kit) and $13 \mu \mathrm{l}$ $\mathrm{ddH}_{2} \mathrm{O}$. The PCR protocol was as follows: Initial denaturation at $95^{\circ} \mathrm{C}$ for $3 \mathrm{~min}$; followed by 40 cycles of denaturation at $95^{\circ} \mathrm{C}$ for $30 \mathrm{sec}$ and annealing at $60^{\circ} \mathrm{C}$ for $30 \mathrm{sec}$ (iQ5; Bio-Rad Laboratories, Inc., Hercules, CA, USA). The $2^{-\Delta \Delta C q}$ method was used to calculate the relative expression of miR-215 against GAPDH (21). Each sample was tested in triplicate.

Cell Counting Kit (CCK)-8 assay. A549 cells in the NC and miR-215 mimic groups were seeded into 96-well plates at a density of 5,000 cells/well in triplicate. Every $24 \mathrm{~h}$, the cells were incubated at $37^{\circ} \mathrm{C}$ with $20 \mu \mathrm{l} \mathrm{CCK}-8$ reagent (Beyotime Institute of Biotechnology, Shanghai, China) for $30 \mathrm{~min}$. Absorbance at $490 \mathrm{~nm}$ was read on a microplate reader (168-1000; Model 680; Bio-Rad Laboratories, Inc.) at 24, 48 and $72 \mathrm{~h}$, and proliferation curves were plotted using absorbance values at each time point.

Transwell assays. Transwell chambers ( $8-\mu \mathrm{m}$ pore diameter and 24 wells; Corning Incorporated, Corning, NY, USA) were used to evaluate the migratory ability of A549 cells. Transfected cells were collected by trypsin digestion, and resuspended at a density of $2 \times 10^{5}$ cells $/ \mathrm{ml}$ using DMEM. The cell suspension $(200 \mu \mathrm{l})$ was added into the upper chamber. In the lower chamber, $500 \mu 1$ DMEM supplemented with $10 \%$ FBS was added. Following incubation for $24 \mathrm{~h}$, the cells in the 
upper chamber were wiped using a cotton swab. Subsequently, the cells in the lower chamber were fixed using $4 \%$ formaldehyde for $10 \mathrm{~min}$ at room temperature, and then subjected to Giemsa staining at room temperature for $1 \mathrm{~min}$. Following three washes with PBS, cells that migrated to the lower side of the chamber were counted under a light microscope (five fields; magnification, x200) to evaluate migratory ability.

Matrigel invasion chambers (BD Biosciences, Franklin Lakes, NJ, USA) were used to determine the invasive ability of cells. Matrigel was first diluted with serum-free DMEM at a ratio of $1: 2$. In the upper chamber $\left(10^{5}\right.$ cells), $50 \mu$ l diluted Matrigel was added and kept at $37^{\circ} \mathrm{C}$ for $1 \mathrm{~h}$. In the lower chamber, $500 \mu \mathrm{l}$ DMEM supplemented with $10 \%$ FBS was added. Following incubation for $72 \mathrm{~h}$, the cells in upper chamber were wiped with a cotton swab. Then, the chamber was fixed using $4 \%$ formaldehyde for $10 \mathrm{~min}$ at room temperature, and then subjected to Giemsa staining at room temperature for $1 \mathrm{~min}$. Subsequent to three washes with PBS, cells that moved to the lower side of the chamber were counted under a light microscope (five fields; magnification, $\mathrm{x} 200$ ) to evaluate invasive ability.

Western blotting. At $48 \mathrm{~h}$ after transfection, cells were trypsinized and collected by centrifugation at $12,000 \mathrm{x}$ g at $4^{\circ} \mathrm{C}$ for $10 \mathrm{~min}$. Following this, precooled radioimmunoprecipitation assay lysis buffer $(600 \mu \mathrm{l} ; 50 \mathrm{mM}$ Tris-base, $1 \mathrm{mM}$ EDTA, $150 \mathrm{mM} \mathrm{NaCl}, 0.1 \%$ SDS, $1 \%$ TritonX-100, and $1 \%$ sodium deoxycholate; Beyotime Institute of Biotechnology) and phenylmethylsulfonyl fluoride were added to the samples. Subsequent to lysis for $5 \mathrm{~min}$ on ice, the mixture was centrifuged at $12,000 \mathrm{x} \mathrm{g} / \mathrm{min}$ at $4^{\circ} \mathrm{C}$ for $10 \mathrm{~min}$. The supernatant was used to determine protein concentration using a bicinchoninic acid protein concentration determination kit [cat. no. RTP7102; Real-Times (Beijing) Biotechnology Co., Ltd., Beijing, China]. Protein samples $(50 \mu \mathrm{g})$ were then mixed with an equal volume of $2 X$ SDS loading buffer prior to denaturation in a boiling water bath for $10 \mathrm{~min}$. Afterwards, the samples $(5 \mu \mathrm{l})$ were subject to $10 \%$ SDS-PAGE at $100 \mathrm{~V}$. The resolved proteins were transferred to polyvinylidene difluoride membranes on ice $(300 \mathrm{~mA}$, $2 \mathrm{~h}$ ) and blocked with 5\% skimmed milk at room temperature for $1 \mathrm{~h}$. Subsequently, the membranes were incubated with rabbit anti-human MMP-16 polyclonal primary antibody (1:1,000; cat. no. ab73877; Abcam, Cambridge, UK) and mouse anti-human GAPDH primary antibody (1:5,000; cat. no. ab8245; Abcam) at $4^{\circ} \mathrm{C}$ overnight. Following extensive washing with PBS with Tween-20 (five times, 5 min each), the membranes were incubated, respectively, with goat anti-mouse horseradish peroxidase (HRP)-conjugated secondary antibody for GAPDH (1:5,000; cat. no. ab6789; Abcam) and goat anti-rabbit HRP-conjugated secondary antibody for MMP-16 (1:2,000; cat. no. ab205718; Abcam) for $1 \mathrm{~h}$ at room temperature. Following this, the membranes were washed with PBS with Tween-20, five times for $5 \mathrm{~min}$ each. The membrane was subsequently developed with an enhanced chemiluminescence detection kit (Sigma-Aldrich; Merck KGaA, Darmstadt, Germany) for imaging. Image Lab v3.0 software (Bio-Rad Laboratories, Inc.) was used to acquire and analyze imaging signals. The relative content of MMP-16 protein was expressed as the MMP-16/GAPDH ratio.

Bioinformatics. Bioinformatics prediction is a powerful tool for the study of the functions of miR. To understand the regulatory mechanism of MMP-16, TargetScan (release 7.1; targetscan.org) was utilized to predict miR molecules that may regulate MMP-16.

Dual-luciferase reporter assay. The potential target genes of miR-215 were predicted using bioinformatics. miR-215 was identified to be capable of binding with the 3'-UTR of MMP-16 mRNA. According to bioinformatics results, wild-type (WT) and mutant seed regions of miR-215 in the 3'-UTR of MMP-16 gene were chemically synthesized in vitro, with the addition of the SpeI and HindIII restriction sites, and then cloned into pMIR-REPORT luciferase reporter plasmids (Beyotime Institute of Biotechnology). Plasmids $(0.5 \mu \mathrm{g})$ with WT or mutant 3'-UTR DNA sequences were co-transfected with miR-215 mimics into A549 cells using Lipofectamine ${ }^{\circledR} 2000$ (Thermo Fisher Scientific, Inc.). Following cultivation for $24 \mathrm{~h}$, the cells were lysed using a dual-luciferase reporter assay kit (Promega Corporation, Madison, WI, USA) according to the manufacturer's manual, and fluorescence intensity was measured using a GloMax 20/20 luminometer (Promega Corporation). Using Renilla fluorescence activity as an internal reference, the fluorescence value of each group of cells was measured.

Statistical analysis. The results were analyzed using SPSS 16.0 (SPSS, Inc., Chicago, IL, USA). All measurement data were expressed as the mean \pm standard deviation. Intergroup comparison was performed using paired Student's t-tests. The results among multiple groups were compared using one-way analysis of variance followed by Bonferroni's post hoc test. $\mathrm{P}<0.05$ was considered to indicate a statistically significant difference.

\section{Results}

Reduced expression of miR-215 in NSCLC is negatively associated with lymphatic metastasis and TNM staging. To measure the expression of miR-215 in NSCLC tissues, RT-qPCR was employed. The data demonstrated that the level of miR-215 in tumor tissues was significantly lower than that in tumor-adjacent tissues $(\mathrm{P}<0.05$; Fig. $1 \mathrm{~A})$. In addition, the expression of miR-215 in patients with lymphatic metastasis (N1) was significantly lower than that in patients with no lymphatic metastasis (N0) $(\mathrm{P}<0.05$; Fig. 1B). Similarly, the expression level of miR-215 in patients at TNM stages III and IV was significantly lower than that in patients at stages I or II and all groups were significantly different from each other $(\mathrm{P}<0.05$; Fig. 1C). The results suggest that the reduced expression of miR-215 in NSCLC is negatively associated with lymphatic metastasis and TNM staging.

Overexpression of $\mathrm{miR}-215$ inhibits the proliferation of A549 cells in vitro. To determine the effect of miR-215 on the proliferation of A549 cells, RT-qPCR and a CCK-8 assay were used. The data revealed that miR-215 expression in A549 cells transfected with miR-215 mimics was significantly higher than that in cells transfected with miR-NC ( $\mathrm{P}<0.05$; Fig. 2A). In addition, A549 cells transfected with miR-215 mimics had significantly lower absorbance at $490 \mathrm{~nm}$ compared with those transfected with miR-NC at 24 and $48 \mathrm{~h}$ ( $\mathrm{P}<0.05$; Fig. 2B). The results indicate that overexpression of miR-215 inhibits the proliferation of A549 cells in vitro. 

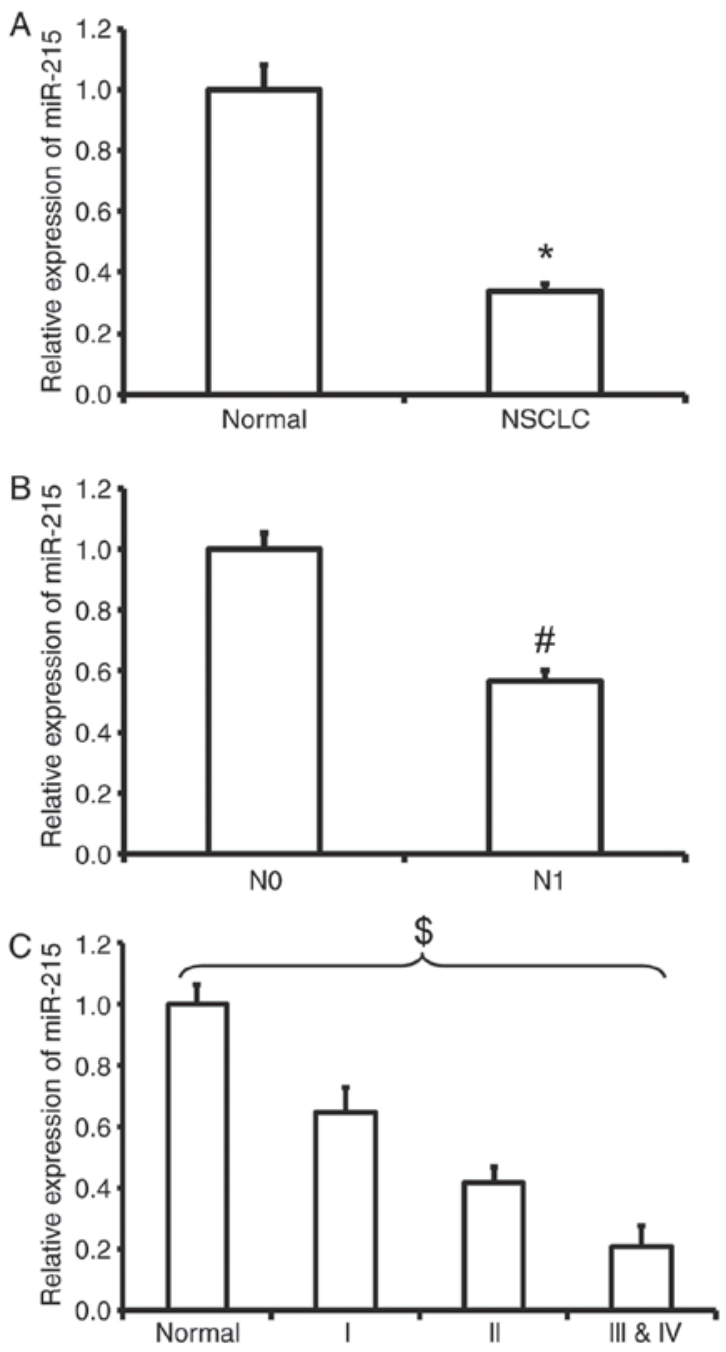

Figure 1. Expression of miR-215 in NSCLC and its clinical significance. (A) Relative expression of miR-215 in NSCLC tissues and tumor-adjacent normal tissues. (B) Relative expression of miR-215 in patients in groups N1 and N0. (C) Relative expression of miR-215 in patients at TNM stages I, II and III/IV. The data in multiple groups were compared using one-way analysis of variance followed by a post hoc test. ${ }^{~} \mathrm{P}<0.05$ vs. normal tissues; ${ }^{~} \mathrm{P}<0.05$ vs. N0; ${ }^{\$} \mathrm{P}<0.05$ as indicated. miR, microRNA; NSCLC, non-small cell lung carcinoma; N1, lymphatic metastasis; N0, without lymphatic metastasis.

Upregulated expression of miR-215 inhibits the migration and invasion of $A 549$ cells in vitro. To examine the migration and invasion of A549 cells, Transwell assays were performed. Migration assay demonstrated that the number of cells in the miR-215 mimics group that migrated through the chamber membrane was significantly lower than that in the miR-NC group $(\mathrm{P}<0.05$; Fig. 3). Similarly, the invasion assay demonstrated that the number of invaded cells in the miR-215 mimics group was significantly smaller than that in the miR-NC group $(\mathrm{P}<0.05$; Fig. 3). These results suggest that upregulated expression of miR-215 inhibits the migration and invasion of A549 cells in vitro.

$M M P-16$ is a potential target of miR-215. In the present study, TargetScan was used to identify target sequences of miR-215. The analysis revealed 212 transcripts with conserved sites, and it was demonstrated that MMP-16 was a potential target of miR-215, containing two conserved sites in the 3'-UTR. To
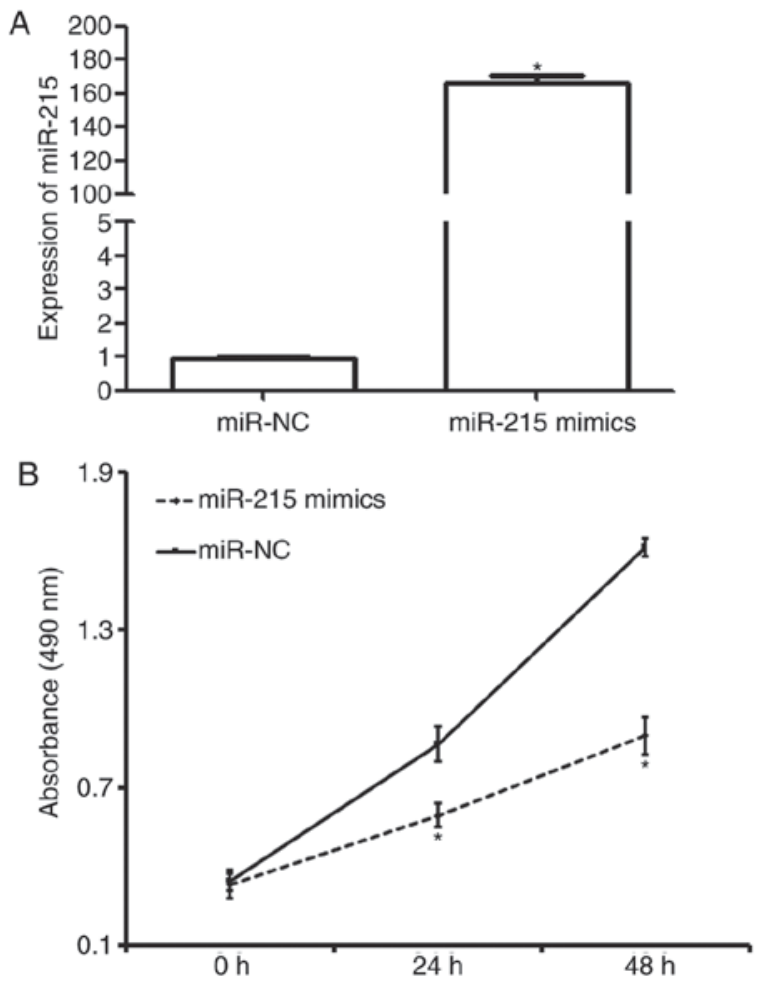

Figure 2. Effect of miR-215 on the proliferation of A549 cells in vitro. (A) Expression level of miR-215 in A549 cells determined by reverse transcription-quantitative polymerase chain reaction. (B) Proliferation of A549 cells. A549 cells were transfected with miR-215 mimics or miR-NC, and a Cell Counting Kit- 8 assay was performed to measure the absorbance $(490 \mathrm{~nm})$ of the cells at 0,24 and $48 \mathrm{~h}$. A cell proliferation curve was plotted. ${ }^{*} \mathrm{P}<0.05 \mathrm{vs}$. miR-NC group. miR, microRNA; NC, negative control.

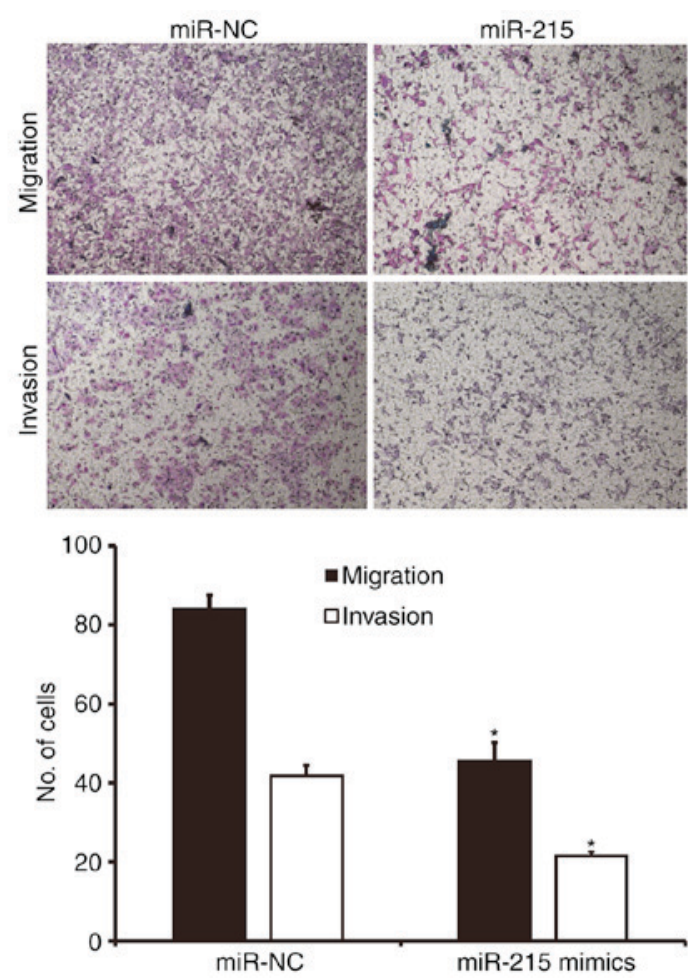

Figure 3. Effect of miR-215 on the migration and invasion of A549 cells in vitro. A549 cells were transfected with miR-215 mimics or miR-NC, and migratory and invasive abilities of the cells were determined using Transwell assays. Magnification, $\mathrm{x} 100$. " $\mathrm{P}<0.05$ vs. with corresponding miR-NC group. miR, microRNA; NC, negative control. 

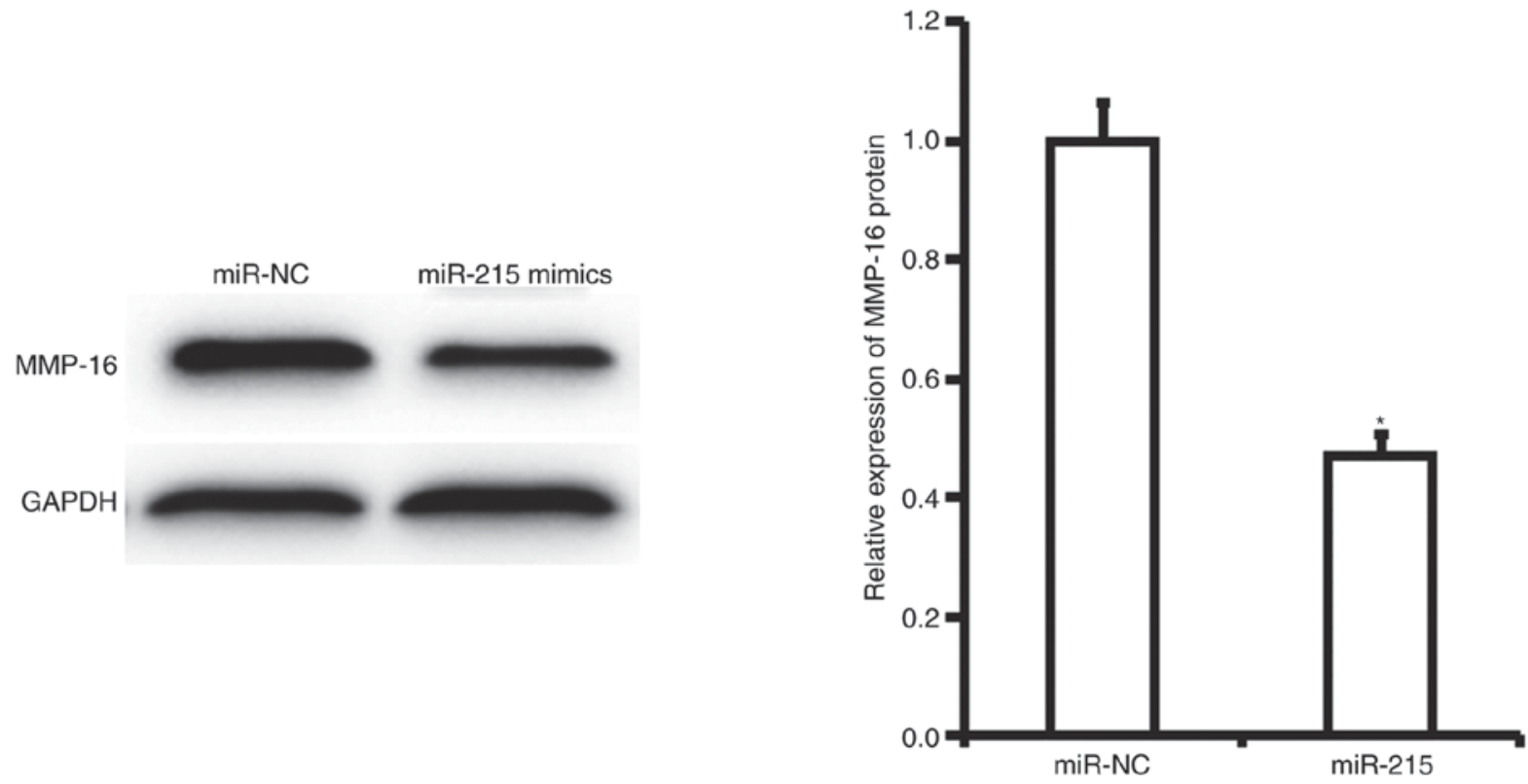

Figure 4. Effect of miR-215 on the expression of MMP-16 protein in A549 cells. Western blotting was used to determine protein expression. ${ }^{*} \mathrm{P}<0.05$ vs. miR-NC. miR, microRNA; MMP-16, matrix metalloproteinase-16; NC, negative control.

A

C

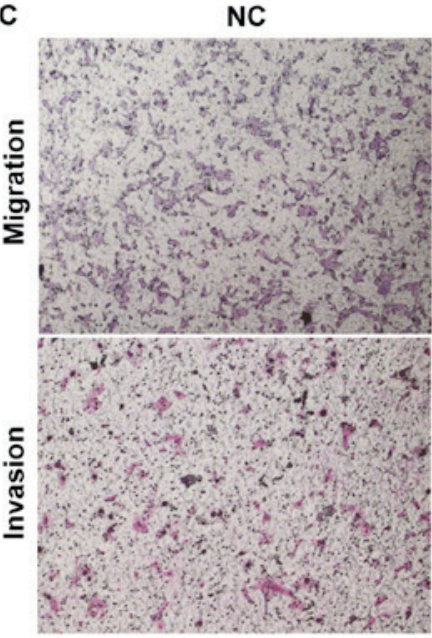

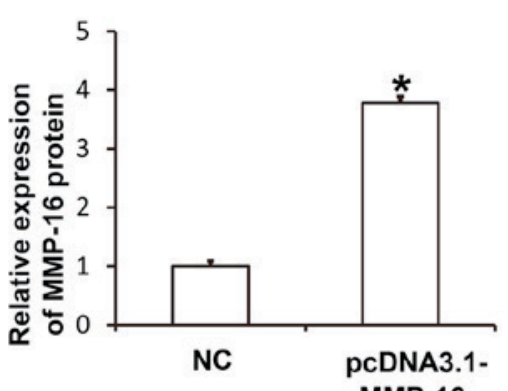

MMP-16

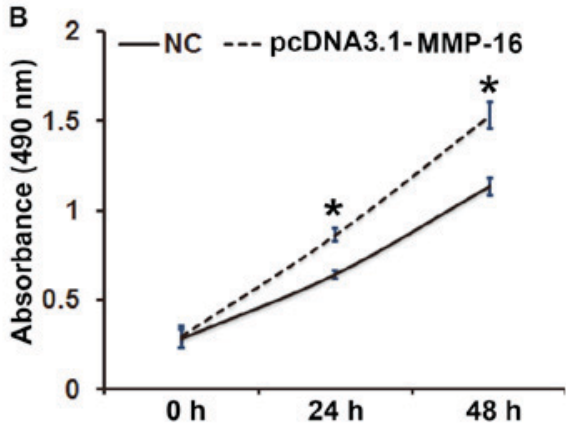

pcDNA3.1-MMP-16
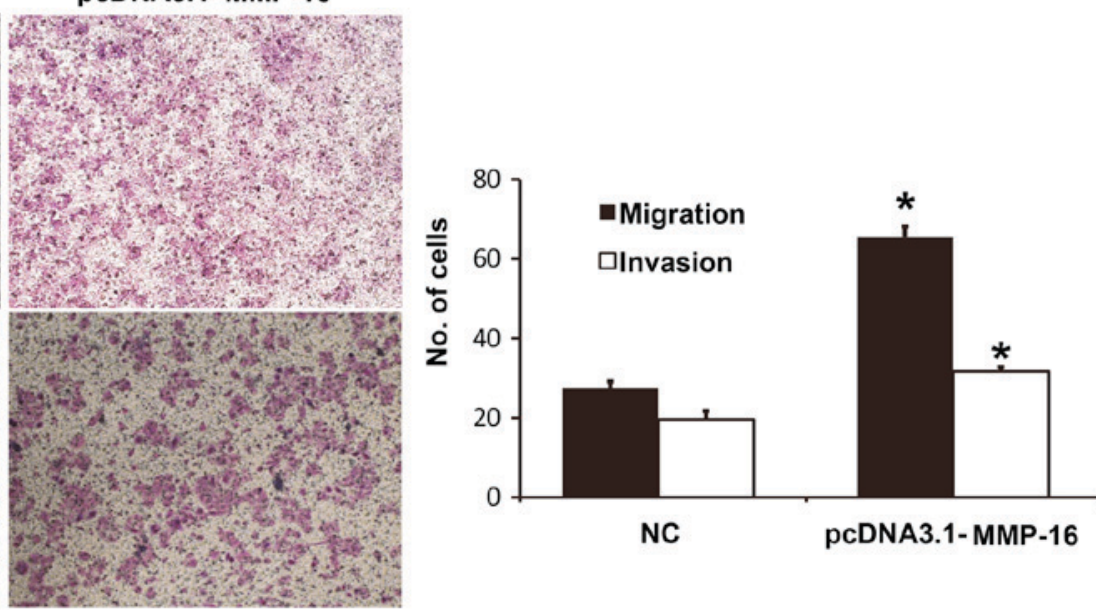

Figure 5. Effect of MMP-16 on the biological functions of A549 cells. (A) Expression of MMP-16 protein in A549 cells transfected with NC or pcDNA3.1-MMP-16 plasmids. Western blotting was used to determine protein expression. (B) Proliferation of A549 cells transfected with NC or pcDNA3.1-MMP-16 plasmids. A Cell Counting Kit-8 assay was used to measure the absorbance $(490 \mathrm{~nm}$ ) of the cells at 0, 24 and $48 \mathrm{~h}$. A cell proliferation curve was plotted. (C) Migration and invasion of A549 cells transfected with NC or pcDNA3.1-MMP-16 plasmids. Migratory and invasive abilities of the cells were determined using Transwell assays. Magnification, $\mathrm{x} 100$. "P<0.05 vs. the NC group. MMP-16, matrix metalloproteinase-16; NC, negative control.

the best of our knowledge, there have been no previous reports claiming that miR-215 could directly regulate MMP-16
mRNA. However, it is well established that MMP-16 serves a crucial role in multiple cancer types and may be regulated by 
A

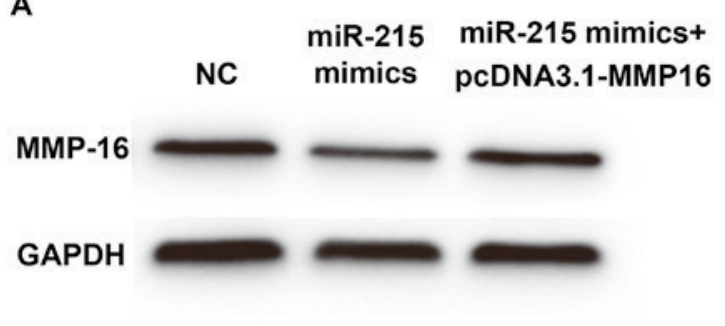

B $\rightarrow$ NC

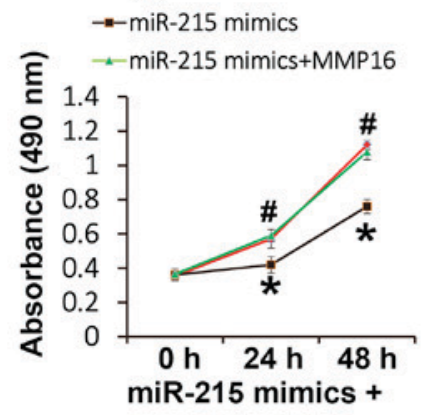

C

NC miR-215 mimics pcDNA3.1-MMP16
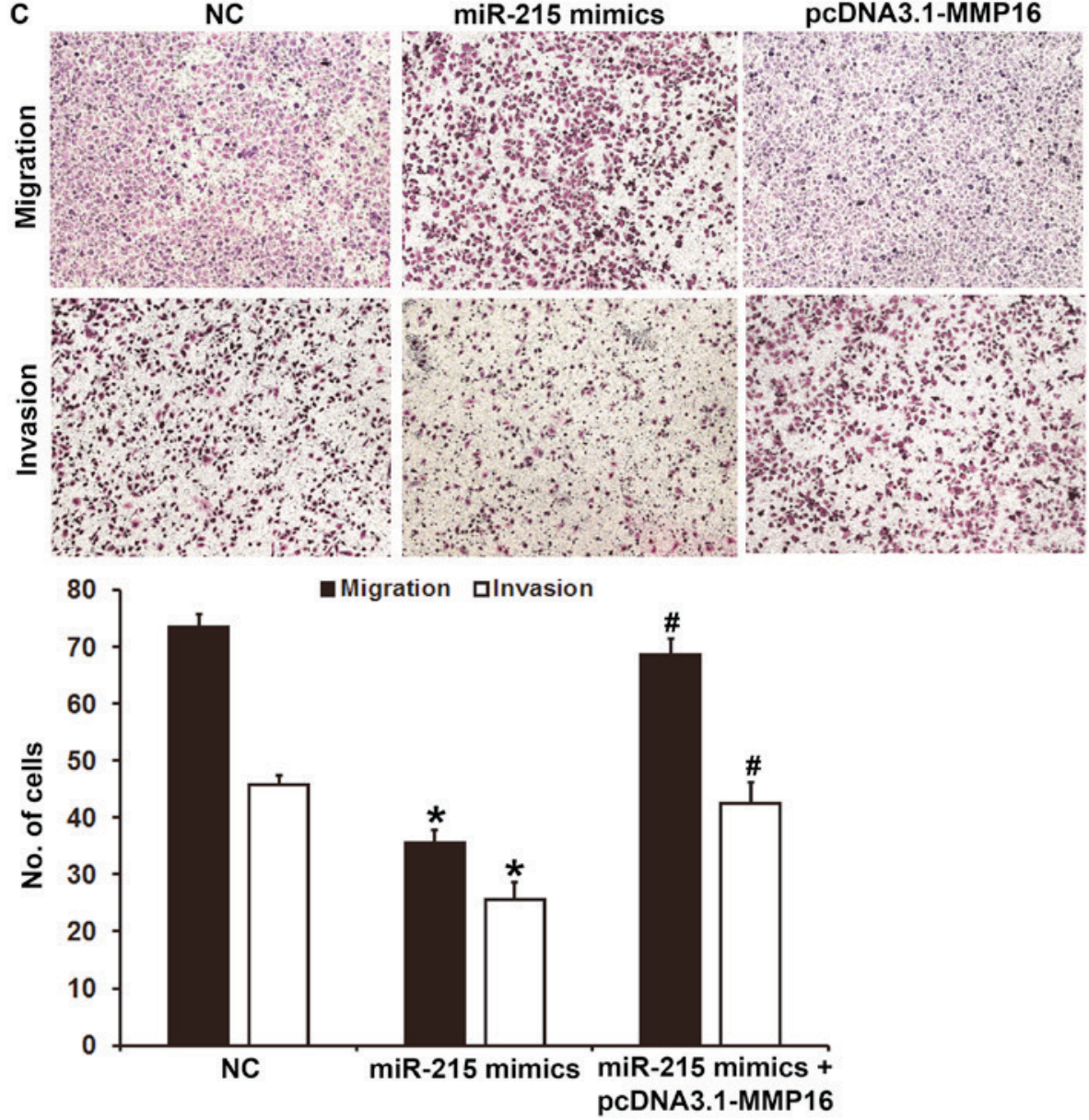

Figure 6. Effect of miR-215 and MMP-16 on the biological functions of A549 cells. (A) Expression of MMP-16 protein in A549 cells transfected with NC, miR-215 or miR-215 and pcDNA3.1-MMP-16 plasmids. Western blotting was used to measure protein expression. (B) Proliferation of A549 cells transfected with NC, miR-215 or miR-215 and pcDNA3.1-MMP-16 plasmids. A Cell Counting Kit-8 assay was used to measure the absorbance (490 nm) of the cells at 0, 24 and $48 \mathrm{~h}$. A cell proliferation curve was plotted. (C) Migration and invasion of A549 cells transfected with NC, miR-215 or miR-215 and pcDNA3.1-MMP-16 plasmids. Migratory and invasive abilities of the cells were determined using Transwell assays. Magnification, x100. The data in multiple groups for migration or invasion assays were compared using one way analysis of variance followed by a post hoc test. ${ }^{\text {}} \mathrm{P}<0.05$ vs. the NC group; ${ }^{*} \mathrm{P}<0.05 \mathrm{vs}$. the miR-215 mimics group. miR, microRNA; MMP-16, matrix metalloproteinase-16; NC, negative control.

miR (15). The result suggests that MMP16 is a potential target of miR-215 (data not shown).

miR-215 may exert its biological functions by regulating the expression of MMP-16. To determine the effect of miR-215 on the expression of MMP-16 protein in A549 cells, western blotting was performed. Western blotting results demonstrated that expression of MMP-16 protein in A549 cells with overexpression of miR-215 was significantly lower than that in cells of the miR-NC group $(\mathrm{P}<0.05$; Fig. 4). This result suggests that miR-215 may exert its biological functions by regulating the expression of MMP-16.
Elevated expression of MMP-16 promotes the proliferation, migration and invasion of A549 cells. To determine the biological function of MMP-16 in A549 cells, the cells were transfected with NC and pcDNA3.1-MMP-16 plasmids. Western blotting revealed that MMP-16 protein expression in A549 cells transfected with pcDNA3.1-MMP-16 was significantly higher than that in the NC group ( $\mathrm{P}<0.05$; Fig. 5A). CCK- 8 assay demonstrated that A549 cells transfected with pcDNA3.1-MMP16 had significantly higher absorbance at $490 \mathrm{~nm}$ than those transfected with NC at 24 and $48 \mathrm{~h}(\mathrm{P}<0.05$; Fig. 5B). Transwell assays indicated that the numbers of migrated or invaded cells 


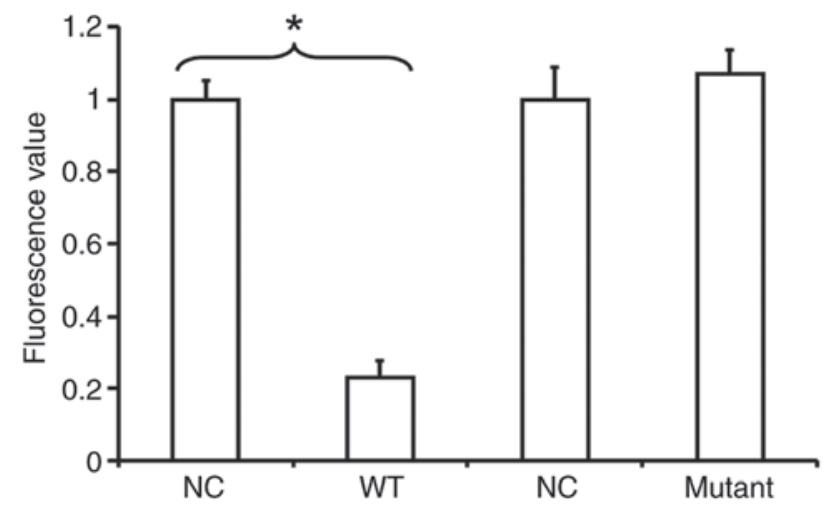

Figure 7. Identification of interaction between miR-215 and MMP-16. Results of the dual-luciferase reporter assay. Plasmids $(0.5 \mu \mathrm{g})$ with WT or mutant 3'-untranslated region DNA sequences were co-transfected with miR-215 mimics into A549 cells. Following cultivation for $24 \mathrm{~h}$, the cells were lysed using a dual-luciferase reporter assay kit and fluorescence intensity was measured using GloMax 20/20 luminometer. Using Renilla fluorescence activity as an internal reference, the fluorescence values of each group of cells were measured. " $\mathrm{P}<0.05$ as indicated. miR, microRNA; MMP-16, matrix metalloproteinase-16; WT, wild-type; NC, negative control.

in the pcDNA3.1-MMP16 group were significantly higher than those in the $\mathrm{NC}$ group $(\mathrm{P}<0.05$; Fig. 5C). These results indicate that elevated expression of MMP-16 promotes the proliferation, migration and invasion of A549 cells.

miR-215 regulates the proliferation, migration and invasion of A549 cells via MMP-16. To determine whether miR-215 regulates the proliferation, migration and invasion of A549 cells via the MMP-16 protein, A549 cells were co-transfected with pcDNA3.1-MMP-16 and miR-215 mimics. Western blotting demonstrated that MMP-16 protein expression in A549 cells transfected with miR-215 mimics was lower than that in the NC group, while co-transfection with miR-215 mimics and pcDNA3.1-MMP-16 increased the expression level of MMP-16 (Fig. 6A). CCK-8 assay revealed that A549 cells transfected with miR-215 mimics had significantly lower absorbance at $490 \mathrm{~nm}$ than those transfected with $\mathrm{NC}$ at 24 and $48 \mathrm{~h}(\mathrm{P}<0.05)$; while co-transfection with miR-215 mimics and pcDNA3.1-MMP-16 significantly increased the absorbance at $490 \mathrm{~nm}$ compared with that in the miR-215 mimics group at 24 and $48 \mathrm{~h}(\mathrm{P}<0.05$; Fig. 6B). Transwell assays indicated that the numbers of migrated or invaded cells in the miR-215 mimics group were significantly lower than those in the $\mathrm{NC}$ group $(\mathrm{P}<0.05)$; however, co-transfection with miR-215 mimics and pcDNA3.1-MMP-16 significantly increased these numbers compared with that in the miR-215 mimics group ( $\mathrm{P}<0.05$; Fig. 6C). These results suggest that $\mathrm{miR}-215$ regulates the proliferation, migration and invasion of A549 cells via MMP-16.

miR-215 binds with the 3'-UTR seed region of MMP-16 $m R N A$. To identify the interaction between miR-215 and the 3'-UTR of MMP-16 mRNA, a dual-luciferase reporter assay was performed. The fluorescence value of cells co-transfected with miR-215 mimics and pMIR-REPORT-WT luciferase reporter plasmids was significantly lower than that in the NC group $(\mathrm{P}<0.05)$. By contrast, the fluorescence value of cells co-transfected with miR-215 mimics and pMIR-REPORT-mutant luciferase reporter plasmids was not significantly different from that in the NC group ( $\mathrm{P}>0.05$; Fig. 7). This result indicates that miR-215 binds with the 3'-UTR seed region of MMP-16 mRNA.

\section{Discussion}

miR-215 is a newly discovered miR molecule that is associated with tumors. The expression of miR-215 is induced by p53 and it inhibits tumor growth by regulating cell cycle checkpoint protein expression (22). Studies have revealed that the expression of miR-215 is reduced in multiple tumors, and that it is negatively associated with the metastasis and prognosis of tumors. For example, Wang et al (23) reported that reduced expression of miR-215 in peripheral blood of patients with acute myeloid leukemia is associated with a poor prognosis. Zhou et al (24) demonstrated that expression of miR-215 is closely related to the prognosis of patients with breast cancer, and the lower the expression, the lower the 5-year survival rate. The present study indicated that expression of miR-215 in NSCLC is significantly decreased. In the comparison between lymphatic metastasis and TNM staging, it was revealed that the expression of miR-215 in the group with lymphatic metastasis was lower than that in the non-metastatic group, and the expression of miR-215 in patients at stages III/IV was significantly lower than that of patients at stages I/II. These results suggest that miR-215 may have the biological functions of a tumor suppressor gene in NSCLC. However, another report revealed that the expression of miR-215 is upregulated in some tumors types, and promotes the proliferation, metastasis and invasion of tumor cells. It was demonstrated that miR-215 expression in gastric cancer cells is upregulated and promotes the drug resistance, proliferation, migration and invasion of gastric cancer cells (16). This suggests that the expression and biological function of miR-215 may be dependent on the tumor type.

Studies have indicated that miR-215 inhibits the proliferation, metastasis and invasion of tumor cells by targeting multiple genes in vitro. For example, Chen et al (25) reported that miR-215 inhibits the proliferation, migration and invasion of colon cancer cells by targeting Yin-Yang 1 gene. Li et al (17) revealed that miR-215 suppresses the proliferation, migration and invasion of pancreatic cancer cells by targeting the ZEB2 gene. Additionally, Hou et al (26) discovered that miR-215 inhibits the invasion and metastasis of NSCLC by targeting the ZEB2 gene. Similarly, the present study demonstrated that expression of miR-215 inhibits the proliferation, migration and invasion of lung cancer A549 cells, and downregulated expression of miR-215 may promote the occurrence and development of lung cancer. Notably, the present data indicate that miR-215 serves the role of a tumor suppressor gene by targeting MMP-16 gene expression, suggesting that miR-215 has more than one target gene in lung cancer.

MMP-16 is a membrane-type metalloproteinase, and it takes effect by activating proMMP-2 (gelatinase A) that is produced by cells (27). Studies have demonstrated that MMP-16 promotes the proliferation, metastasis and invasion of tumors. For example, Cao et al (28) reported that MMP-16 promotes the proliferation, invasion and metastasis of gastric cancer, and its expression is directly related to the prognosis of patients with gastric cancer. In addition, miR-146b-5p inhibits pancreatic cancer progression 
by downregulating MMP-16 expression (29). The present data indicate that overexpression of miR-215 downregulates the expression of MMP-16 in A549 cells, and overexpression of MMP-16 inhibits the effects of miR-215 on the proliferation, migration and invasion of A549 cells. In addition, overexpression of MMP-16 itself promotes the proliferation, migration and invasion of A549 cells. Dual-luciferase reporter assays in the present study revealed that miR-215 is able to directly bind to the 3'-UTR of MMP-16 to exert its biological functions.

Taken together, the present study demonstrates that decreased expression of MMP-16 induced by miR-215 suppresses the proliferation, metastasis and invasion of NSCLC cells. In addition, miR-215 may be a target for the therapy of NSCLC. In the future, the expression of MMP-16 in NSCLC tissues compared with normal controls will be examined, and its association with miR-215 expression and patient prognosis will be investigation. In addition, the association between miR-215 expression and NSCLC subtype will also be explored in future studies.

\section{Acknowledgements}

We would like to thank Dr Jie Li of the Department of Chest Surgery, Ningbo No. 2 Hospital (Ningbo, China) for his valuable help.

\section{Competing interests}

The authors declare that they have no competing interests.

\section{References}

1. Kaira K, Tomizawa Y, Imai H, Sakurai R, Matsuura M, Yoshii A Ochiai M, Kotake M, Ebara T, Saitoh JI, et al: Phase I study of nab-paclitaxel plus carboplatin and concurrent thoracic radiotherapy in patients with locally advanced non-small cell lung cancer. Cancer Chemother Pharmacol 79: 165-171, 2017.

2. Dong Z, Zhao L, Lu S, Xiong J and Geng Z: Overexpression of TSPAN8 promotes tumor cell viability and proliferation in nonsmall cell lung cancer. Cancer Biother Radiopharm 31: 353-359, 2016.

3. Presley CJ, Soulos PR, Tinetti M, Montori VM, Yu JB and Gross CP: Treatment burden of medicare beneficiaries with stage I non-small-cell lung cancer. J Oncol Pract 13: e98-e107, 2017.

4. Qiu ZL, Shen CT, Sun ZK, Wei WJ, Zhang XY, Song HJ and Luo QY: Circulating long non-coding rnas act as biomarkers for predicting 131I uptake and mortality in papillary thyroid cancer patients with lung metastases. Cell Physiol Biochem 40: 1377-1390, 2016.

5. Liu TC, Hsieh MJ, Wu WJ, Chou YE, Chiang WL, Yang SF, Su SC and Tsao TC: Association between survivin genetic polymorphisms and epidermal growth factor receptor mutation in non-small-cell lung cancer. Int J Med Sci 13: 929-935, 2016.

6. Ma L, Qiu B, Zhang J, Li QW, Wang B, Zhang XH, Qiang MY, Chen ZL, Guo SP and Liu H: Survival and prognostic factors of non-small cell lung cancer patients with postoperative locoregional recurrence treated with radical radiotherapy. Chin J Cancer 36: 93, 2017.

7. Wei WE, Mao NQ, Ning SF, Li JL, Liu HZ, Xie T, Zhong JH, Feng Y, Wei CH and Zhang LT: An analysis of EGFR mutations among 1506 cases of non-small cell lung cancer patients in Guangxi, China. PLoS One 11: e0168795, 2016.

8. Ghafoor Q, Baijal S, Taniere P, O'Sullivan B, Evans M and Middleton G: Epidermal growth factor receptor (EGFR) kinase inhibitors and non-small cell lung cancer (NSCLC)-advances in molecular diagnostic techniques to facilitate targeted therapy. Pathol Oncol Res: Dec 21, 2017 (Epub ahead of print).

9. Wang T, Xu X, Xu Q, Ren J, Shen S, Fan C and Hou Y: miR-19a promotes colitis-associated colorectal cancer by regulating tumor necrosis factor alpha-induced protein 3-NF- $\mathrm{kB}$ feedback loops. Oncogene 36: 3240-3251, 2017.
10. Labourier E, Lloyd M, Andruss B, Adai A and Schwarzbach A: An miRNA assay for the classification of benign and neoplastic lesions in pancreatic fine-needle aspirates. J Clin Oncol 29 (4 Suppl): S163, 2011.

11. Huang G, Pan J, Ye Z, Fang B, Cheng W and Cao Z: Overexpression of miR-216b sensitizes NSCLC cells to cisplatin-induced apoptosis by targeting c-Jun. Oncotarget 8: 104206-104215, 2017.

12. Pei K, Zhu JJ, Wang CE, Xie QL and Guo JY: MicroRNA-185-5p modulates chemosensitivity of human non-small cell lung cancer to cisplatin via targeting ABCC1. Eur Rev Med Pharmacol Sci 20: 4697-4704, 2016

13. Sun CC, Li SJ, Zhang F, Zhang YD, Zuo ZY, Xi YY, Wang L and Li DJ: The novel miR-9600 suppresses tumor progression and promotes paclitaxel sensitivity in non-small-cell lung cancer through altering STAT3 expression. Mol Ther Nucleic Acids 5: e387, 2016.

14. Wang P, Deng Y and Fu X: MiR-509-5p suppresses the proliferation, migration, and invasion of non-small cell lung cancer by targeting YWHAG. Biochem Biophys Res Commun 482: 935-941, 2017.

15. Wei Y, Sun J and Li X: MicroRNA-215 enhances invasion and migration by targeting retinoblastoma tumor suppressor gene 1 in high-grade glioma. Biotechnol Lett 39: 197-205, 2017.

16. Li N, Zhang QY, Zou JL, Li ZW, Tian TT, Dong B, Liu XJ, Ge S, Zhu Y, Gao J and Shen L: miR-215 promotes malignant progression of gastric cancer by targeting RUNX1. Oncotarget 7: 4817-4828, 2016.

17. Li QW, Zhou T, Wang F, Jiang M, Liu CB, Zhang KR, Zhou Q, Tian Z and Hu KW: MicroRNA-215 functions as a tumor suppressor and directly targets ZEB2 in human pancreatic cancer. Genet Mol Res 14: 16133-16145, 2015.

18. Chen B, Huang Z, Zhang Y, Chen Y and Li Z: MicroRNA-145 suppresses osteosarcoma metastasis via targeting MMP16. Cell Physiol Biochem 37: 2183-2193, 2015.

19. Arslan D, Bozcuk H, Gunduz S, Tural D, Tattli AM, Uysal M, Goksu SS, Bassorgun Cİ, Koral L, Coskun HS, et al: Survival results and prognostic factors in T4 N0-3 non-small cell lung cancer patients according to the AJCC 7th edition staging system. Asian Pac J Cancer Prev 15: 2465-2472, 2014.

20. Ahmad J, Baig MA, Ali AA, Al-Huqail A, Ibrahim MM and Qureshi MI: Comparative assessment of four RNA extraction methods and modification to obtain high-quality RNA from Parthenium hysterophorus leaf. 3 Biotech 7: 373, 2017.

21. Livak KJ and Schmittgen TD: Analysis of relative gene expression data using real-time quantitative PCR and the 2(-Delta Delta C(T)) method. Methods 25: 402-408, 2001.

22. Georges SA, Biery MC, Kim SY, Schelter JM, Guo J, Chang AN, Jackson AL, Carleton MO, Linsley PS, Cleary MA and Chau BN: Coordinated regulation of cell cycle transcripts by p53-inducible microRNAs, miR-192 and miR-215. Cancer Res 68: 10105-10112, 2008.

23. Wang YX, Zhang TJ, Yang DQ, Yao DM, Yang L, Zhou JD, Deng ZQ, Ma JC, Guo H, Wen XM, et al: Reduced miR-215 expression predicts poor prognosis in patients with acute myeloid leukemia. Jpn J Clin Oncol 46: 350-356, 2016.

24. Zhou SW, Su BB, Zhou Y, Feng YQ, Guo Y, Wang YX, Qi P and $\mathrm{Xu}$ S: Aberrant miR-215 expression is associated with clinical outcome in breast cancer patients. Med Oncol 31: 259, 2014.

25. Chen Z, Han S, Huang W, Wu J, Liu Y, Cai S, He Y, Wu S and Song W: MicroRNA-215 suppresses cell proliferation, migration and invasion of colon cancer by repressing Yin-Yang 1. Biochem Biophys Res Commun 479: 482-488, 2016.

26. Hou Y, Zhen J, Xu X, Zhen K, Zhu B, Pan R and Zhao C: miR-215 functions as a tumor suppressor and directly targets ZEB2 in human non-small cell lung cancer. Oncol Lett 10: 1985-1992, 2015.

27. Zhang WL, Chen YF, Meng HZ, Du JJ, Luan GN, Wang HQ, Yang MW and Luo ZJ: Role of miR-155 in the regulation of MMP-16 expression in intervertebral disc degeneration. J Orthop Res 35: 1323-1334, 2017.

28. Cao L, Chen C, Zhu H, Gu X, Deng D, Tian X, Liu J and Xiao Q: MMP16 is a marker of poor prognosis in gastric cancer promoting proliferation and invasion. Oncotarget 7: 51865-51874, 2016.

29. Lin F, Wang X, Jie Z, Hong X, Li X, Wang M and Yu Y: Inhibitory effects of miR-146b-5p on cell migration and invasion of pancreatic cancer by targeting MMP16. J Huazhong Univ Sci Technolog Med Sci 31: 509-514, 2011.

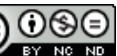

This work is licensed under a Creative Commons Attribution-NonCommercial-NoDerivatives 4.0 International (CC BY-NC-ND 4.0) License. 